\title{
The Use of Magnesium Sulphate in the Management of Severe Preeclampsia and eclampsia in Bayelsa State, Nigeria
}

\author{
Alabintei $\mathrm{OM}^{1}$, Abasi IJ ${ }^{2 *}$ and Alabrah $\mathrm{PW}^{1}$ \\ ${ }^{1}$ Department of Obstetrics and Gynaecology, Federal Medical Centre, Nigeria \\ ${ }^{2}$ Department of Obstetric and Gynaecology, Niger Delta University Teaching Hospital, Nigeria \\ Submission: April 09, 2021; Published: April 21, 2021 \\ *Corresponding author: IJ Abasi, Department of Obstetric and Gynaecology, Niger Delta University Teaching Hospital, Nigeria
}

Abstract

Background: Several Studies on severe pre-eclampsia/eclampsia (Severe PE/E) in Nigeria reflects gross underuse of $\mathrm{MgSO}_{4}$. This study was conceptualized to determine $\mathrm{MgSO}_{4}$ use and factors affecting it among healthcare workers (HCWs) in the management of severe PE/E in public health facilities in Bayelsa State.

Methods: Using a self-administered, structured questionnaire and an in-depth interview guide/checklist, quantitative and qualitative data were collected from 115 HCWs and 29 health facility managers respectively in 16 randomly selected health facilities in Bayelsa state. Availability of $\mathrm{MgSO}_{4}$, ease of use among HCWs were determined by scoring 6 questions testing $\mathrm{MgSO}_{4}$. HCWs were categorized as 'not comfortable', 'slightly comfortable' and 'very comfortable' with $\mathrm{MgSO}_{4}$ use. Chi-square test and Binary logistic regression explored determinants of $\mathrm{MgSO}_{4}$ use among respondents. The in-depth interviews were analyzed along thematic areas using NVivo 11.0 QSR software. Significance level was $p<0.05$.

Results: HCWs who participated in the quantitative part of the study were nurses (40.0\%), doctors (37.4\%) and CHEW/CHO (22.6\%). $\mathrm{MgSO}_{4}$ availability was reported by $71.6 \%$ of respondents while slightly above half $(56.8 \%)$ were very comfortable $\mathrm{MgSO}_{4}$ use in managing severe $\mathrm{PE} / \mathrm{E}$. Checklist revealed availability in only $25.0 \%$ of facilities visited. Factors affecting its use included level of care (Secondary level: OR - 7.65; p - 0.002) and level of knowledge among HCWs (good knowledge: OR - 6.14; p-0.003). Unavailability of guidelines for its use, inadequate drugs, financial constraints, lack of training were reasons identified from the in-depth interviews.

Conclusion: The supply of $\mathrm{MgSO}_{4}$ is poor and many HCWs are not comfortable with its use in in Bayelsa state. This would have a negative impact on the management of severe PE/E. It is imperative that routine training on the management of severe PE/E with particular focus on $\mathrm{MgSO}_{4}$ use be instituted in the state in ensure quality care for women with severe PE/E.

Keywords: Pre-eclampsia; Eclampsia; Magnesium sulphate; Management

\section{Introduction}

Hypertensive disorders during pregnancy are major causes of severe morbidity, long-term disability, and death of mothers and their babies. In addition to maternal morbidity and mortality, PE/E can also increase the likelihood of preterm delivery or stillbirth [1]. Globally, about 10 to $20 \%$ of maternal deaths are associated with eclampsia. About $3-10 \%$ of women would experience hypertension during pregnancy [2-5] and slightly less than $8 \%$ of pregnancies get complicated by pre-eclampsia $[5,6]$. Among the pre-eclamptic patients, about $10 \%$ develop severe pre-eclampsia and eclampsia (PE/E) [7-9] and the risk of dying from PE/E is approximately 300 times higher for women in developing countries compared with women in developed countries [10]. It is well documented that
$99 \%$ of the approximately 303,000 maternal deaths occurring annually worldwide are in low-resourced, developing countries $[7,11]$ and between 50 to 70 thousand women are thought to die annually from complications resulting from preeclampsia and eclampsia [12,13]. In resource-poor countries, the incidence of eclampsia varies widely, and findings suggest that the incidence rate varies from between 1 in 100 to 1 in 17009, [14]. In Nigeria, its prevalence ranges between $2 \%$ to $16.7 \%$ [15-17].

The morbidities accrued from PE/E are preventable through timely detection and management of complications during and after pregnancy [7]. As early as 1925, magnesium sulfate $\left(\mathrm{MgSO}_{4}\right)$ was first introduced to control convulsion, but it was the 
collaborative Eclampsia Trial in 1995 that confirmed the superior efficacy of $\mathrm{MgSO}_{4}$ in the treatment of severe preeclampsia and eclampsia when compared with other anti-convulsants [18]. A randomized, placebo-controlled study (the Magpie trial) in which 33 countries with four centres in Nigeria (Ibadan, Sagamu, PortHarcourt and Sokoto) participated, showed that women treated with $\mathrm{MgSO}_{4}$ had a $52 \%$ lower recurrence of convulsions than those treated with diazepam and $67 \%$ lower recurrence than those treated with phenytoin [19].

A review of research on pre-eclampsia/eclampsia conducted in Nigeria reflects the gross underuse of $\mathrm{MgSO}_{4}$ as a life-saving therapeutic drug. This is as a result of ignorance of its use, lack of applicable treatment guidelines, lack of training of health workers on its use, wrong perception that the drug is meant for use only at the highest level of facilities, cost, availability, refusal to change from old practices, little incentives for pharmaceutical companies to commercialize the drug and ready availability of pre-packaged forms of less effective drugs [12,17,19-21]. Tukur and colleagues in 2009 discovered that despite MgSO4 recommendation as the most effective, safe and low-cost drug for treating preeclampsia/ eclampsia, it was still largely unavailable in most developing countries [19]. Another study by Tukur et al in 2013 which focused on introducing $\mathrm{MgSO}_{4}$ and training health care providers on updated evidence-based interventions, and this resulted in a significant reduction in case fatality rate $[12,19]$.

Oguntunde et al. [22], undertook a research in Sokoto and Bauchi to check for facilitating and enabling factors in the use of $\mathrm{MgSO}_{4}$ for managing PE/E. They discovered that less than half of health providers had ever been trained on the correct use of $\mathrm{MgSO}_{4}$ and that even with those that were trained, regular supervision, which would serve as a tool to strengthen the local health system, $\mathrm{w}$ was not done [22]. They also reported that the facilities studied lacked the basic and essential equipment and supplies including electricity, water, $\mathrm{MgSO}_{4}$, and clinical guidelines required to successfully manage PE/E22. Rawlins et al. [23] in 2018, conducted a study across six sub-Saharan African countries [22]. It was discovered that $\mathrm{MgSO}_{4}$ was available in $16 \%$ and $100 \%$ in Ethiopia and Mozambique respectively. They also found out that though $\mathrm{MgSO}_{4}$ was present on their essential drug list, its uptake was fraught with difficulties in many countries [24]. These included absence of national guidelines, lack of registration of the drug in some of these countries, as well as uncertainty by health workers about the safety profile and the use of the drug.

The current WHO regimen for $\mathrm{MgSO}_{4}$ is a somewhat complex regimen. It requires intravenous (IV) and intramuscular (IM) administration of $\mathrm{MgSO}_{4}$ at different doses for both loading and maintenance doses. It requires a $20 \%$ dilution for the IV loading dose, which requires health providers to calculate the quantity of sterile water to add to the $\mathrm{MgSO}_{4}$ solution $[21,25]$. Most health providers do not encounter eclampsia very often; and when they do, trying to remember this complex regimen is daunting. In a hospital based prospective study done in Assiut University Hospital, Egypt to evaluate the protocol used for management of eclampsia at this hospital, it was found that $\mathrm{MgSO}_{4}$ was able to control convulsions in $98.1 \%$ of the 1998 eclamptic women who were recruited in the study from 1990 to 2010; and there was only $4 \%$ mortality [26].

In another study conducted in Sokoto, the "ultra - short therapy" of magnesium sulphate in eclampsia, it was shown that a loading dose of $14 \mathrm{gm}$ of $\mathrm{MgSO}_{4}$ prevented $92.6 \%$ of eclampsia and only $7 \%$ of patients needed maintenance doses, hence showing that this ultra-short therapy can be beneficial if the patients that present in primary health centres are given at least the loading dose before referral [25]. This underlines the high efficacy of $\mathrm{MgSO}_{4}$ in the management of pre-eclampsia as well as eclampsia. Considering that Nigeria is a developing country and that preeclampsia/eclampsia-related maternal mortalities are prevalent in low-resourced, developing countries [7,11], there is a need to identify the current management modalities of preeclampsia and eclampsia in Bayelsa state, Nigeria especially regarding the use of $\mathrm{MgSO}_{4}$. Also, there are no current published literature about the use of $\mathrm{MgSO}_{4}$ in the management of cases of pre-eclampsia or eclampsia in Bayelsa state. It thus became necessary to conduct this study to determine the health care providers use of $\mathrm{MgSO}_{4}$ in the management of severe preeclampsia and eclampsia in public health facilities in Bayelsa State as well as factors affecting its use. This study therefore aimed at identifying gaps in obstetric health care services across the three levels of care in Bayelsa state with regards to the use of $\mathrm{MgSO}_{4}$ in managing preeclampsia/eclampsia, as this knowledge can be utilized as a basis for initiating strategies and policies targeted at improving the management of obstetric hypertensive complications.

\section{Materials and Methods}

A mixed-method descriptive design was used for conducting this research assessing the management of severe preeclampsia and eclampsia using $\mathrm{MgSO}_{4}$ in Bayelsa state. Bayelsa state comprises three senatorial districts. The units of analysis were health facilities in the three senatorial districts of the State. Sample size for the quantitative aspect of the study was calculated using the sample size formula for descriptive studies $[27,28]$. The sample size was adjusted to compensate for non-response, using a non-response rate of $10 \%$. Altogether, a total of 155 workers were recruited for the quantitative part of the study. For the qualitative aspect, using purposive sampling 29 , health facility managers were selected for the in-depth interviews.

A multi-stage sampling technique was employed to select health facilities for the study. Health facilities were selected from the three senatorial districts of the State. In stage 1, Ogbia local government area (LGA) was selected from the 3LGAs in Bayelsa East senatorial district, and likewise Kolokuma/Opokuma LGA from Bayelsa Central senatorial district and Sagbama LGA from Bayelsa West senatorial district by simple random sampling (balloting). From each of the selected local government areas, one general hospital was selected for the study by simple random sampling (stage 2). From all the primary health centres referring 
patients to the selected General hospitals, 4 primary health centres were selected by simple random sampling (Stage 3). Finally, by simple random sampling (Balloting), the Federal Medical Centre was chosen for the study from the 2 tertiary healthcare facilities in the State. Healthcare providers in the employ of these selected facilities were recruited for the quantitative part of the study. Twenty-nine health facility staff/ managers from the facilities chosen for the study were purposively selected for the key informant interviews (KIIs) using an interview guide. The use of $\mathrm{MgSO}_{4}$ in the management of $\mathrm{PE} / \mathrm{E}$ as well as factors that influenced the use of this drug in the management of severe PE/E in Bayelsa state were further explored in the qualitative part of the study.

The study instruments included a self-administered structured questionnaire and an interview guide. The structured questionnaire was pretested in one primary, secondary and tertiary healthcare centre respectively. The review of the responses from health workers during the pre-test of the questionnaire was useful in modifying some sections of the questionnaire to ensure clarity and to elicit appropriate responses from study respondents.

Mixed methods were used for data collection; this comprised quantitative and qualitative methods. Six research assistants were recruited and trained for the study. The training exposed the research assistants to the objectives and methods of the study. They were trained on the administration of the study questionnaire, the use of the interviewer guide, recording of the interview and how to apply the inventory checklist to ensure that the data collection was systematic and consistent. They were also trained on how to obtain an informed consent from respondents and observe the ethics of medical research. The training was conducted by Experts from the Public health department of the Federal Medical Centre, Yenagoa. The training was followed by a field trial by the trainees supervised by the Public health experts and the principal Investigator before data collection commenced for the actual study.

Respondents were given the questionnaires to fill after the objectives of the study were explained and informed consent was obtained. They were encouraged to fill the questionnaire as soon as possible and return to the research assistants. Respondents were assured of confidentiality of the information provided, which encouraged them to respond sincerely to the questions in the study instrument. The questionnaires were checked for completeness of response and respondents were also encouraged to give answers to any question they might have omitted and if they did not, their decision to complete the questionnaires was completely voluntary. The inventory checklist was administered in the different facilities after informing the officer-in-charge and fixing an appointment he or she was comfortable with. The checklist was administered in the antenatal clinic or wards (where applicable), labour wards (where applicable) and the pharmacy/drug store to sight and quantify commodities, materials and equipment needed in the management of severe PE/E.
The qualitative research method was used to gain insight into the contextual issues on the quality assurance of severe PE/E management across the three levels of care in Bayelsa State, Nigeria. Key Informant Interviews (KIIs) were conducted among Community Health Extension Workers (CHEWs)/ Community Health Officials (CHO), Pharmacists, Pharmacy Technicians, Nurses, hospital-based Medical Doctors and Medical Consultants across the three levels of healthcare in the state. The study took place in four Local Government Areas (LGAs) of the three senatorial districts of the State. Each interview took place in a convenient office/venue chosen by the respondents, to ensure that they were relaxed and provided honest answers. Each interview was conducted by an interviewer and a note taker, with each lasting for an average of 20 minutes. The interviews were also, by consent, recorded so as to recapture any areas the interviewer taking notes might have missed. The interviews commenced with a brief introduction of the interviewers and the respondents, the aim and objectives of the study in general and then the interview proper. All data collection was done using laid down ethical principles.

Data entry, cleaning and analysis were done using the Statistical Package for Social Sciences (SPSS) 22.0 version. Categorical variables were summarized as frequencies and percentages while continuous variables were presented by the most appropriate measures of central tendency and dispersion. The healthcare providers were assessed for their level of knowledge of the use of $\mathrm{MgSO}_{4}$ in the management of severe preeclampsia and eclampsia by allocation of scores to answers provided to questions in the structured questionnaire. The level of knowledge of the respondents was assessed using 36 questions from the study questionnaire. Each correct answer was scored 1 and otherwise was scored zero, giving a total attainable score of 36. To categorize the scores into different levels of knowledge, the mean score and standard deviation of the scores from all the respondents were calculated. Scores above the 'mean score plus one standard deviation' were categorized as good level of knowledge; scores between the 'mean score' and 'mean score plus one standard deviation' were graded as fair level of knowledge while every score below the 'mean score' was considered poor level of knowledge [28]. Factors influencing the use of $\mathrm{MgSO}_{4}$ in the management of severe preeclampsia and eclampsia were assessed by testing for associations between the use of $\mathrm{MgSO}_{4}$ and independent variables like duration of direct work experience in emergency obstetric care, level of practice, availability of $\mathrm{MgSO}_{4}$, availability of protocol guideline etc. using Chi-square test of association and logistic regression where applicable. Significant level was put at $\mathrm{p}$-value of $<0.05$.

A two-step binary logistic regression was carried out to explore factors in the study that influence the level of compliance with the national guideline among study respondents. First, the dependent variable (use of $\mathrm{MgSO}_{4}$ ) was dichotomized to make it suitable for use in a logistic regression analysis. 'Poor' and 'fair' use was recorded as zero ('Non-use') and good level of use coded as one (Use). A univariate binary logistic regression was done between 


\section{Journal of Gynecology and Women's Health}

the recoded dependent variable and explanatory variables in the study (Gender, age, marital status, and professional cadre of respondents, level of care, number of years post qualification etc.) to derive an unadjusted odd ratio for the likelihood of use of $\mathrm{MgSO}_{4}$ among the study respondents. The second step was a multivariate regression analysis where all explanatory variables found to be statistically significant in the univariate regression analysis were used in creating a model that explored their different weighted contributions to the likelihood of use of $\mathrm{MgSO}_{4}$ among study respondents.

Data from the qualitative aspect of the study was transcribed from the recorders with inputs from the notes taken during

Results

Table 1: Sociodemographic characteristic of respondents.

\begin{tabular}{|c|c|}
\hline Variable & Frequency $\mathrm{N}=155(\%)$ \\
\hline \multicolumn{2}{|l|}{ Gender } \\
\hline Male & $52(33.5)$ \\
\hline Female & $103(66.5)$ \\
\hline \multicolumn{2}{|l|}{ Age Group } \\
\hline $21-30$ years & $55(35.5)$ \\
\hline $31-40$ years & $65(41.9)$ \\
\hline $41-50$ years & $30(19.4)$ \\
\hline $51-60$ years & $5(3.2)$ \\
\hline \multicolumn{2}{|c|}{ Mean Age of Respondent $-34.9 \pm 7.64$ years } \\
\hline \multicolumn{2}{|l|}{ Marital Status } \\
\hline Single/Divorced/Widow(er) & $68(43.9)$ \\
\hline Married & $87(56.1)$ \\
\hline \multicolumn{2}{|l|}{ Occupation } \\
\hline Nurse & $62(40.0)$ \\
\hline Doctor & $58(37.4)$ \\
\hline $\mathrm{CHEW} / \mathrm{CHO}$ & $35(22.6)$ \\
\hline \multicolumn{2}{|l|}{ Level of Care } \\
\hline Primary & $57(36.8)$ \\
\hline Secondary & $29(18.7)$ \\
\hline Tertiary & $69(44.5)$ \\
\hline \multicolumn{2}{|l|}{ Post Qualification Working Years } \\
\hline Less than 1 year & $10(6.5)$ \\
\hline $1-5$ years & $49(31.6)$ \\
\hline $6-10$ years & $52(33.5)$ \\
\hline Greater than 10 years & $44(28.4)$ \\
\hline \multicolumn{2}{|c|}{ Mean Post Qualification working years $-8.98 \pm 7.58$ years } \\
\hline \multicolumn{2}{|l|}{ Working Years in Present Facility } \\
\hline Less than 1 year & $50(32.3)$ \\
\hline 1 - 5 years & $80(51.6)$ \\
\hline $6-10$ years & $20(12.9)$ \\
\hline Greater than 10 years & $5(3.2)$ \\
\hline
\end{tabular}

the interviews. All the written and recorded materials were transcribed in English. The analysis followed the analytic hierarchy: from data management to descriptive and explanatory account. Thematic analysis was done using the NVivo 11.0 QSR software. Transcribed interviews were imported directly into NVivo and the heading styles (from the interview guide) were used to group the responses into thematic areas. Each interview was read through and four main themes were coded. The identified themes were then pooled together and used to develop a summary for the study findings. Approval for the study was obtained from the ethical committee of the Federal Medical Centre, Yenagoa and the Bayelsa State Ministry of Health.

\section{Results from Quantitative Part of the Study Sociodemographic Characteristic of Respondents}


Of the 155 respondents in the quantitative study, majority were female $(66.5 \%)$. The mean age of the respondents was $34.9 \pm 7.6$ years, and the highest proportion (41.9\%) were aged between 31-40 years. More than half of the respondents were married (56.1\%). Nurses constituted the highest proportion (40.0\%), followed by doctors (37.4\%) and others were the CHEW/ CHO (22.6\%). Majority worked at the tertiary level of healthcare (44.5\%), and $36.8 \%$ worked in the primary level of healthcare. The mean post-qualification working years was $8.98 \pm 7.58$ years, with $33.5 \%$ of respondents having 6-10 years working experience. About half of the respondents had 1-5 working years in the present facility, and a third had less than a year experience in the present facility. This data is shown on Table 1.

Upon enquiry about how comfortable they were with the use of MgSO4 in the management of pre-eclampsia or eclampsia, majority of them 88 (56.8\%) were very comfortable, 25(16.1\%) slightly comfortable and $18(11.6 \%)$ were not comfortable at all with using $\mathrm{MgSO}_{4}$ for these purposes. Also, 111 (71.6) of the respondents were of the opinion that they had $\mathrm{MgSO}_{4}$ in their health facilities. This drug was found to be mostly available in the secondary health facilities compared to the primary and tertiary facilities. This is shown in Table 2.

Table 2: Ease of $\mathrm{MgSO}_{4}$ use among the health workers.

\begin{tabular}{|c|c|}
\hline Characteristics & Frequency (\%) \\
\hline MgSO4 availability in the health facility $(\mathrm{n}=155)$ & $111(71.6)$ \\
\hline Yes & $39(25.2)$ \\
\hline No & $5(3.2)$ \\
\hline No response & $21(36.8)$ \\
\hline MgSO4 availability in the health facility $(\mathrm{n}=111)$ & $28(96.6)$ \\
\hline Primary & $62(89.9)$ \\
\hline Secondary & $18(11.6)$ \\
\hline Tertiary & $25(16.1)$ \\
\hline How comfortable are you in using MgSO ${ }_{4} ?(\mathrm{n}=131)$ & $88(56.8)$ \\
\hline Not comfortable at all & \\
\hline Slightly Comfortable & \\
\hline Very Comfortable & \\
\hline
\end{tabular}

Factors affecting the use of MgSO4 in the management of severe $\mathrm{PE} / \mathrm{E}$

Though $\mathrm{MgSO}_{4}$ was present in one (8.3\%) primary and two $(66.6 \%)$ secondary health facilities visited, no guide on how to administer and monitor the patients was available. Other challenges that were identified by the respondents included inadequate drugs, financial constraint on the patient's side especially if told to procure the necessary drugs, inadequate space, poor compliance to medication amongst others. This is shown in Table 3.

Table 3: Challenges suggested by Study participants that may be affecting the care of patients with Severe preeclampsia and eclampsia.

\begin{tabular}{|c|c|}
\hline Identified Challenges & Frequency (\%) \\
\hline Inadequate drugs (e.g. $\left.\mathrm{MgSO}_{4}\right)$ & $44(37.3 \%)$ \\
\hline Inadequate Space & $11(9.3 \%)$ \\
\hline Inadequate personnel & $10(8.5 \%)$ \\
\hline Poor compliance to medication & $11(9.3 \%)$ \\
\hline Refusal of Admission & $3(2.5 \%)$ \\
\hline Financial constraint & $23(25.4 \%)$ \\
\hline Late presentation & $9(7.6 \%)$ \\
\hline Others & $6(5.0 \%)$ \\
\hline
\end{tabular}


Determinants of the use of magnesium sulphate in the management of $\mathrm{PE} / \mathrm{E}$

As shown in Table 4, it can be seen that professional cadre, level of care of the facility in which the respondent works, number of years post professional qualification, number of patients seen

Table 4: Determinants of the use of magnesium sulphate. by respondents and the level of knowledge are factors that affect the use of $\mathrm{MgSO}_{4}$. Further subjection to multivariate logistic regression gave adjusted odds ratios that showed that only level of care (secondary level: O.R. - 7.65; 95\% C.I: 2.10 - 27.97; p: 0.002) and level of knowledge (good level of knowledge: O.R. - 6.14; 95\% C.I: 1.69 - 22.37) remained significant. This is shown in Table 5.

\begin{tabular}{|c|c|c|}
\hline \multicolumn{3}{|c|}{ Bivariate Analysis } \\
\hline Variable (Reference Group) & Crude OR $(95 \% \mathrm{CI})$ & P-Value \\
\hline \multicolumn{3}{|l|}{ Gender (Female) } \\
\hline Male & $1.95(0.94-4.05)$ & 0.071 \\
\hline \multicolumn{3}{|l|}{ Age Group (51 - 60 Years) } \\
\hline $21-30$ years & $2.471(0.26-23.62)$ & 0.432 \\
\hline $31-40$ years & $1.532(0.16-14.64)$ & 0.711 \\
\hline $41-50$ years & $0.44(0.04-5.39)$ & 0.524 \\
\hline \multicolumn{3}{|l|}{ Marital Status (Married) } \\
\hline Single/Divorced & $0.86(0.43-1.75)$ & 0.682 \\
\hline \multicolumn{3}{|l|}{ Professional Cadre (CHEW/CHO) } \\
\hline Nurse & $1.92(0.63-5.82)$ & 0.252 \\
\hline Doctor & $3.943(1.34-11.65)$ & $0.013^{*}$ \\
\hline \multicolumn{3}{|l|}{ Level of Care (Primary Level) } \\
\hline Secondary level & $9.11(2.98-27.81)$ & $<0.001^{*}$ \\
\hline Tertiary Level & $3.98(1.49-10.68)$ & $0.006^{*}$ \\
\hline \multicolumn{3}{|c|}{ Post Qualification No of Years ( $>10$ years) } \\
\hline$<1$ year & $1.32(0.23-7.59)$ & 0.755 \\
\hline $1-5$ years & $3.07(1.13-8.30)$ & $0.027^{*}$ \\
\hline $6-10$ years & $2.35(0.86-6.38)$ & 0.094 \\
\hline \multicolumn{3}{|c|}{ No of years in Present facility ( $>10$ years) } \\
\hline$<1$ year & $1.56(0.16-15.16)$ & 0.704 \\
\hline $1-5$ years & $1.93(0.21-18.10)$ & 0.566 \\
\hline $6-10$ years & $0.70(0.06-8.70)$ & 0.786 \\
\hline \multicolumn{3}{|c|}{ No Of Patient Seen Last One Month (No Patient) } \\
\hline $1-5$ Patients & $2.10(0.89-4.93)$ & 0.087 \\
\hline 6 - 10 Patients & $3.16(0.96-10.35)$ & 0.058 \\
\hline$>10$ Patients & $7.36(1.27-42.87)$ & $0.026^{*}$ \\
\hline \multicolumn{3}{|c|}{ Level of Knowledge of Disease (Poor level of Knowledge) } \\
\hline Fair level of Knowledge & $3.677(1.42-9.55)$ & $0.008^{*}$ \\
\hline Good level of Knowledge & $6.196(2.39-16.06)$ & $0.001^{*}$ \\
\hline
\end{tabular}

\section{Qualitative aspect of the study}

A total of 29 health care workers comprising the facility heads or their deputies and the pharmacy heads who were directly involved in the management of the different public health facilities that manage severe preeclampsia/eclampsia in Bayelsa State were purposively selected for the key-informant interview (KII). Of the 16 facilities visited, 3 facilities (18.8\%) had one health worker working as the facility head and the pharmacy head. These 3 facilities were at the primary level of care. Majority of the respondents in the KIIs were female (58.6\%). Of the 18 facility heads, 8 (44.4\%) were doctors, matron/nursing officers were 4 $(22.2 \%)$ and CHEW/CHO were 6 (33.3\%). There were 8 pharmacy heads and 3 pharmacy technicians. $52 \%$ of respondents had spent less than 4 years in the facility they managed.

In order to ascertain the availability of the drug at the facility as at the time of this study, the question, 'is the drug presently available in your facility as we speak' was raised. To this effect, Figure 1 showed the responses in which $37.9 \%$ confirmed $\mathrm{MgSO}_{4}$ was available, $48.3 \%$, said it was not available and $13.8 \%$ of respondents did not know (Figure 1). 


\section{Journal of Gynecology and Women's Health}

Table 5: Determinants of the use of Magnesium sulphate.

\begin{tabular}{|c|c|c|}
\hline \multicolumn{3}{|c|}{ Multivariate Analysis } \\
\hline Variable (Reference group) & Adjusted OR (95\% CI) & p-value \\
\hline \multicolumn{3}{|l|}{ Professional Cadre (CHEW/CHO) } \\
\hline Nurse & $0.42(0.10-1.71)$ & 0.226 \\
\hline Doctor & $0.53(0.11-2.62)$ & 0.436 \\
\hline \multicolumn{3}{|l|}{ Level of Care (Primary Level) } \\
\hline Secondary level & $7.65(2.10-27.97)$ & $0.002^{*}$ \\
\hline Tertiary Level & $2.05(0.60-7.02)$ & 0.256 \\
\hline \multicolumn{3}{|c|}{ Post Qualification No of Years ( $>10$ years) } \\
\hline$<1$ year & $0.71(0.09-5.47)$ & 0.739 \\
\hline $1-5$ years & $1.49(0.44-5.01)$ & 0.519 \\
\hline $6-10$ years & $1.39(0.43-4.51)$ & 0.579 \\
\hline \multicolumn{3}{|c|}{ No Of Patient Seen Last One Month (No Patient) } \\
\hline 1 - 5 Patients & $1.66(0.56-4.92)$ & 0.357 \\
\hline 6 - 10 Patients & $1.96(0.44-5.01)$ & 0.372 \\
\hline$>10$ Patients & $4.52(0.55-37.41)$ & 0.162 \\
\hline \multicolumn{3}{|c|}{ Level Of Knowledge Of Disease (Poor Level Of Knowledge) } \\
\hline Fair level of Knowledge & $2.87(0.99-8.35)$ & 0.052 \\
\hline Good level of Knowledge & $6.14(1.69-22.37)$ & $0.006^{*}$ \\
\hline
\end{tabular}

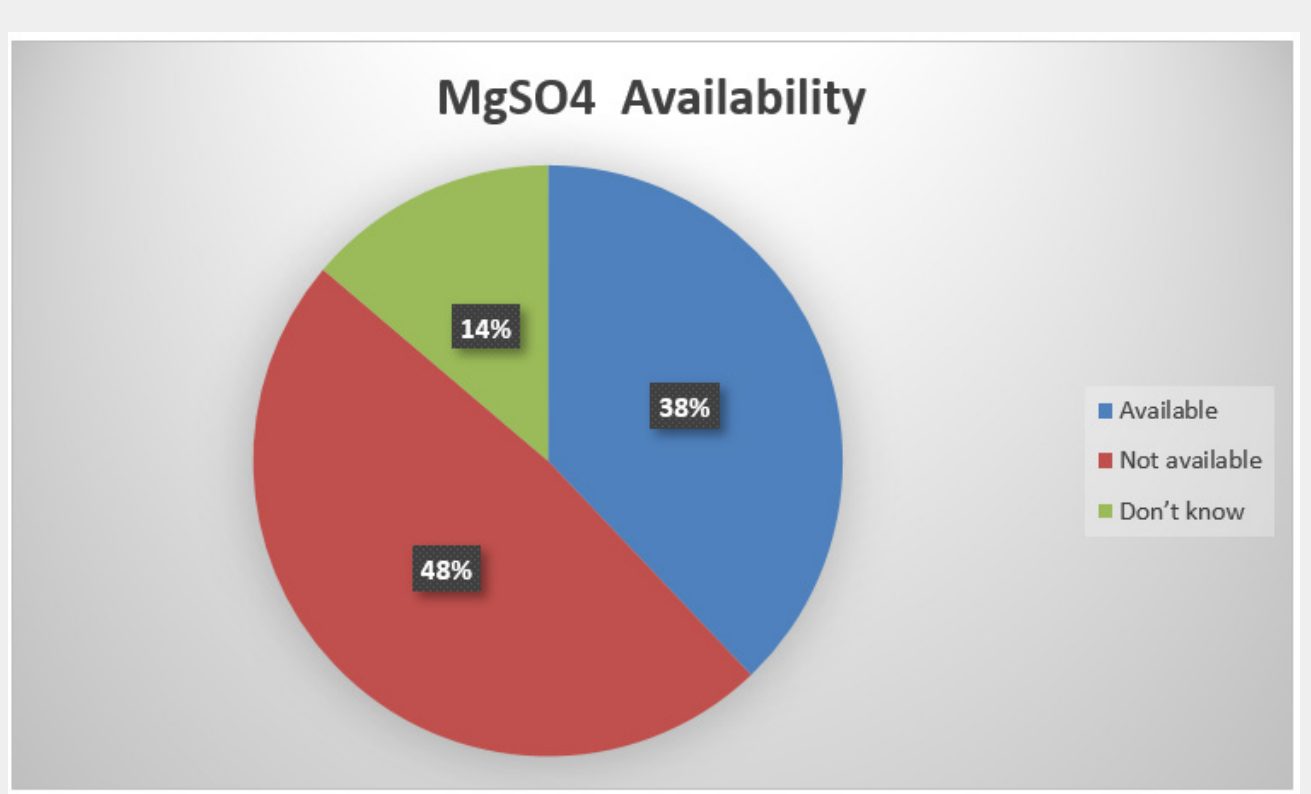

Figure 1: Availability of $\mathrm{MgSO}_{4}$ at the facility as at the time of the study.

\section{Health workers' training on the use of $\mathrm{MgSO}_{4}$}

The health managers and pharmacist in charge were asked about training of their health workers, which would increase their knowledge of the management of severe PE/E. Results from the interviews showed that few of the respondents reported to have been trained or reported the availability of training on the management of preeclampsia/eclampsia for their staff. The supporting quote from the staff is given in Table 6 . 
Table 6: Supporting quote of the respondents.

\begin{tabular}{|c|c|}
\hline Knowledge on Use of Mgso $_{4}$ & Quotes \\
\hline \multirow{2}{*}{$\begin{array}{c}\text { Presence of training } \\
\text { 'We don't have but we know that we are being trained, we are all taught, so we used that idea' ‘They called } \\
\text { for training. The state called for training at the LGA level, we went there to be trained, and we were given } \\
\text { a guideline to follow. The guideline prescribes the rudiments for the management of preeclampsia cases, } \\
\text { including magnesium sulphate but I don't know where or when it was developed. I don't know maybe it is a } \\
\text { national guideline either' }\end{array}$} \\
\hline
\end{tabular}

\section{Availability and Applicability of evidence and current} Practice for management of PE/E

Responses to this thematic area reflected that health personnel especially those at primary health facilities refer these kinds of cases quickly to higher levels of care. Referrals were usually done for reasons that included the absence of doctors in their health facilities and absence of $\mathrm{MgSO}_{4}$ which is needed for the management of pre-eclampsia/eclampsia. Quotes from the health personnel are provided in Table 7.

Table 7: Table showing current practice on management of severe preeclampsia/ eclampsia.

\begin{tabular}{|c|c|c|}
\hline & $\begin{array}{c}\text { Current Practice of Management of } \\
\text { Severe Preeclampsia/ Eclampsia }\end{array}$ & Quotes \\
\hline 1 & Patients are referred early & $\begin{array}{l}\text { 'We usually refer to them early. Once we just see them, we don't even wait for the patient to start } \\
\text { convulsing. When we check her, then if her BP is high, then if we do the urinalysis and we see that } \\
\text { there is protein, we usually refer them early to other health centres that have the facilities and the } \\
\text { wherewithal to take care of her'. 'We refer to Sagbama general hospital' }\end{array}$ \\
\hline 2 & $\begin{array}{c}\mathrm{MgSO}_{4} \text { is not given in primary health } \\
\text { centre }\end{array}$ & $\begin{array}{l}\text { 'We have not managed any patient with severe PE-E, normally this is the primary health centre and } \\
\text { we don't have many drugs and stuff to use. So, I will refer so as not to take much time'. "No (we do not } \\
\text { use), because it (MgSO4) is not used at dispensary level." }\end{array}$ \\
\hline 3 & Tried our best & $\begin{array}{l}\text { 'We managed her BP was ... we were monitoring her BP and her urine output. It came to a time that } \\
\text { there was no even urine output. So, we even gave her referral form. I personally gave her that referral } \\
\text { form. I asked my worker not to attend to her again. We referred her. Before we know, she came back } \\
\text { one night again with labour pain. Thank God that we had magnesium sulphate. That was our saviour. } \\
\text { Because her BP was high, no urine output, even with the drug that we were giving to her too. I think } \\
\text { for } 3 \text { days she did not even urinate. It came to that extent. So, we refer her to Kolo. She did not go } \\
\text { because of the fund. We didn't even know. We had even made up our minds and were at rest that she } \\
\text { had gone. In the night, she just appeared suddenly with labour. Thank God that we had magnesium } \\
\text { sulphate then and we managed it very well and she delivered' } \\
\text { we manage. I've not managed any preeclampsia case. The one I managed, though she was having pre- } \\
\text { eclampsia, we used ehn.... I used hydralazine because BP was } 200 / 160 \text {. So, I've not used magnesium } \\
\text { sulphate, but my doctor called me that he is on his way. Before he could get to the place, the patient } \\
\text { had put to bed'. }\end{array}$ \\
\hline 4 & $\begin{array}{l}\text { Absence of doctor to manage the } \\
\text { condition }\end{array}$ & “We don't give $\mathrm{MgSO}_{4}$ here because we need a separate doctor to manage it." \\
\hline 5 & Unavailability of $\mathrm{MgSO}_{4}$ & $\begin{array}{l}\text { 'I don't think I have seen anyone (referring to MgSO4) for the time been since I have been her } \\
\text { 'We'. } \\
\text { know that they use those drugs for cases like preeclampsia and eclampsia, so we know it like } \\
\text { that but that drug, for this moment I am talking is not here. I have never even used itself, for now } \\
\text { 'We don't use the MgSO4 here because we are not having any case } \\
\text { of preeclampsia here, so we've not even stock that drug once' 'There have been no reasons for the } \\
\text { procurement of MgSO4'. } \\
\text { are up to date and they all are.....all the staff that are working here, they all know about preeclampsia. } \\
\text { Knowing that it is ehn....before you get to an eclamptic patient who is fitting, the next....the first stage } \\
\text { is preeclampsia and those conditions that indicate preeclampsia case, they know about it. So, they } \\
\text { are very much aware and the treatment pattern, the drugs and every other thing else required for the } \\
\text { management of such a case and every other thing that involves preeclamptic situation. I think they } \\
\text { are very much aware of it'. } \\
\text { our current practice on or for the treatment of PEE' } \\
\text { need to improve'. }\end{array}$ \\
\hline
\end{tabular}




\section{Discussion}

In this study, despite the presence of guidelines on managing $\mathrm{PE} / \mathrm{E}$ in some of the health care facilities, there were still inadequacies in using $\mathrm{MgSO}_{4}$ in the management of $\mathrm{PE} / \mathrm{E}$. This study discovered that most of the primary and secondary health care facilities refer patients with PE/E to the tertiary health facility without administering the loading dose of $\mathrm{MgSO}_{4}$ which is required of them. Smith et al. [29] who conducted a global survey across 37 countries and Okonofua et al. [30] in their multi-center study reported that inappropriate policies or lack of clinical protocols contribute to providers' lack of competence and confidence in the use of $\mathrm{MgSO}_{4}$ in the management of severe PE/E as majority of them did not even know the route of administration especially in the primary and secondary health facilities. Access to treatment protocols and guidelines increases the likelihood that PE/E is effectively and efficiently managed if health care providers use these guidelines appropriately. There is also the added advantage that clinical protocols and National guidelines can be used to guide the provision of technical and/or supportive supervision. Other studies have also found that health care providers at highlevel facilities had better knowledge of the management of preeclampsia/eclampsia [31,32]. This might be due to training, more exposure to such cases and the availability of written protocols.

In this study, it was also found that the lack of required drugs, financial constraints, lack of trained personnel, amongst others were among factors that limited the provision of adequate obstetric care, with respect to preeclampsia/eclampsia. Osungbade et al. [33] in a study done at Ibadan noticed that even though $\mathrm{MgSO}_{4}$ has been documented as being effective, it was not routinely administered, and its use was often limited to teaching hospitals. He also noticed that lack of availability of the drug and appropriate health personnel required for its administration as well as cost were recognized obstacles to its use. The continuous availability of $\mathrm{MgSO}_{4}$ especially in the labour ward is critical to arrest convulsions in eclampsia and to prevent progression from severe pre-eclampsia to eclampsia with more fatal outcomes for mothers and newborns.

The primary and secondary health facilities (if incapable of managing the patient with severe PE/E) are supposed to quickly resuscitate and administer the loading dose of $\mathrm{MgSO}_{4}$ before referral. This simple step has been shown to reduce mortality due to this obstetric emergency since most of the mortalities associated with severe PE/E are those seen greater than 12 hours after the last fit [34]. Hence, the earlier a pregnant woman with severe PE/E receives $\mathrm{MgSO}_{4}$ to prevent further fits and its complications, the better the outcome of the management of severe PE/E especially in a place like Bayelsa state where most communities are surrounded by water and means of transportation is difficult to come by. The most common misconception about the use of $\mathrm{MgSO}_{4}$ is the erroneous belief that the drug is highly toxic and there is need for an intensive unit care for women who are to be managed with $\mathrm{MgSO}_{4}$. However, despite the myths and fears related to $\mathrm{MgSO}_{4}$, no other drugs were preferred for treating eclampsia by the providers interviewed in this study. This finding is consistent with another study on the use of MgSO4 from Pakistan [32] in which the preference for $\mathrm{MgSO}_{4}$ was very encouraging as the use of diazepam in women with eclampsia was noticed to be harmful for both the mother and the baby.

It was concluded in this study that there was an inadequacy in the provision of $\mathrm{MgSO}_{4}$ to health facilities assessed in this study and that the use of $\mathrm{MgSO}_{4}$ was limited by certain factors including inadequate drug supply and trained personnel, amongst other factors. It is recommended that health facilities managing obstetric complaints should be well equipped to effectively manage preeclampsia/eclampsia cases. Also, the management of severe pre-eclampsia/eclampsia should be included in regular training of all health care providers with adequate supportive supervision. Task shifting of some duties like administering/loading of $\mathrm{MgSO}_{4}$ to the lower cadre health workers should be implemented in order to make more efficient use of available resources after training them. Lastly, the curriculum for low cadre health care providers training (pre-service) who are involved with pregnant women within communities, such as CHEW/CHO, midwives and nurses should be reviewed, and training should ensure acquisition of competency for dealing with obstetrical emergencies like severe $\mathrm{PE} / \mathrm{E}$.

\section{References}

1. Onyearugha NC, Ugboma AH (2012) Fetal outcome of antepartum and intrapartum eclampsia in Aba, south eastern Nigeria. Trop Doct 42(3): 129-132.

2. Mehta B, Kumar V, Chawla S, Sachdeva S, Mahopatra D, et al. (2015) Hypertension in pregnancy: A community-based study. Indian J Community Med 40(4): 273-278.

3. Muti M, Tshimanga M, Nortion GT, Bangure D, Chonzi P, et al. (2015) Prevalence of pregnancy induced hypertension and pregnancy outcomes among women seeking maternity services in Harare, Zimbabwe. BMC Cardiovasc Disord 15(1): 111.

4. Butalia S, Audibert F, Anne-Marie C, Firoz T, Logan AG, et al. (2018) Hypertensive Canada's 2018 Guidelines for the management of hypertension in pregnancy. Can J Cardiol 34(5): 526-531.

5. Jido TA, Yakassai IA (2013) Preeclampsia: A review of the evidence. Ann Afr Med 12(2): 75-85.

6. Kooffreh ME, Ekott M, Ekpoudom DO (2014) The prevalence of preeclampsia among pregnant women in the university of Calabar Teaching hospital, Calabar. Saudi Journal for health sci 3(3): 133-136.

7. World Health Organization (2011) WHO recommendations for Prevention and treatment of preeclampsia and eclampsia.

8. Thornton C, Dahlen H, Korda A, Hennessy A (2013) The incidence of preeclampsia and eclampsia and associated maternal mortality in Australia from population- linked datasets:2000-2008. Am J Obstet Gynecol 208(6): 476-e1. 
9. Bilano VL, Ota E, Ganchimeg T, Mori R, Souza JP, et al. (2014) Risk factors of preeclampsia/eclampsia and its adverse outcomes in low and middle-income countries: a WHO secondary analysis. PloS one 9(3): e91198.

10. Gaym A, Bailey P, Pearson L, Admasu K, Gebrehiwot Y, et al. (2011) Disease burden due to preeclampsia/eclampsia and the Ethiopian health system's response. Int J Gynecol Obstet 115(1): 112-116.

11. (2018) World Health Organization on maternal mortality-2018.

12. Tukur J, Ahonsi B, Ishaku SM, Araoyinbo I, Okereke E, et al. (2013) Maternal and fetal outcomes after introduction of magnesium sulphate for treatment of preeclampsia and eclampsia in selected secondary facilities: A low-cost Intervention. Matern Child Health J 17(7): 11911198.

13. Ridge A, Eero L, Hill S (2010) Identifying barriers to the availability and use of magnesium sulfate injection in resource poor countries: A case study in Zambia. BMC Health Serv Res 10: 340.

14. Mir AM, Shaikh S, Khan M (2016) Landscaping analysis on preeclampsia and eclampsia in Pakistan.

15. Magee L, Pels A, Helewa M, Rey E, Dadelszen VP, et al. (2014) Diagnosis, evaluation and management of hypertensive disorders of pregnancy. Pregnancy Hypertens 4(2): 105-145.

16. Singh S, Ahmed EB, Egondu SC, Ikechuku NE (2014) Hypertensive disorders in pregnancy among pregnant women in a Nigerian teaching hospital. Niger Med J 55(5): 384-388.

17. Esike CO, Chukwuemeka UI, Anozie OB, Eze JN, Aluka OC, et al. (2017) Eclampsia in Rural Nigeria: The unmitigating catastrophe. Ann Afri Med 16(4): 175-180.

18. Trial CE (1995) Which anticonvulsant for women with eclampsia. Lancet 10(345): 1455-8963.

19. Tukur J (2009) The use of magnesium sulphate for the treatment of preeclampsia and eclampsia. Ann Afr Med 8(2): 76-80.

20. Mirković L, Nejković L, Micić J (2018) A new pathophysiological concept - new classification of pre-eclampsia. Mil Med Pharm J of Serb 75(1): 83-94.

21. Ekele BA (2010) Magnesium sulphate in the treatment of preeclampsia and eclampsia. Tropical J Obstet Gynaecol 27(1): 32-35.

22. Oguntunde O, Charyeva Z, Cannon M, Sambisa W, Orobabon N, et al. (2015) Factors influencing the use of magnesium sulphate in preeclampsia/eclampsia management in health facilities in Northern Nigeria: a mixed method study. BMC Pregnancy childbirth 130(15): 1-8.
23. Rawlins B, Plotkin M, Rakotovao JP, Getachew A, Vaz M, et al. (2018) screening and management of preeclampsia and eclampsia in antenatal, labour and delivery services: findings from cross-sectional observation studies in six sub-saharan African countries. BMC Preg Childbirth 18(1): 346

24. Sheikh S, Qureshi RN, Khowaja AR, Salam R, Vidler M, et al. (2016) Health care provider knowledge and routine management of preeclampsia in Pakistan. Reprod Health 13(Suppl 2): 113-162.

25. Ekele BA, Muhammed D, Bello LN, Namadima IM (2009) Magnesium sulphate therapy in eclampsia: the Sokoto (ultra short) regimen. BMC Res Notes 2: 165.

26. Abd El Aal DE, Shahin AY (2012) Management of eclampsia at Assiut University Hospital, Egypt. Int J Gynecol Obstet 116(3): 232-236.

27. Kirkwood B, Sterne J (2003) Medical Statistics. Med Stat.

28. Varni JW, Limbers CA, Burwinkle TM (2007) Parent proxy-report of their children's health-related quality of life: An analysis of 13,878 parents' reliability and validity across age subgroups using the Peds QLTM 4.0 Generic Core Scales. Health Qual Life Outcomes 5: 1-10.

29. Smith JM, Currie S, Cannon T, Armbruster D, Perri J, et al. (2014) Are national policies and programs for the Prevention and Management of Postpartum Hemorrhage and Pre-Eclampsia/Eclampsia adequate? A key informant survey in 37 countries. Global Health Sci Pract 2(3): 275-284.

30. Okonofua FE, Ogu RN, Fabamwo AO, Ujah IO, Chama CM, et al. (2013) Training health workers for magnesium sulphate use reduces case fatality from eclampsia: results from a multicenter trial. Acta Obstet Gynecol Scand 92(6): 716-720.

31. Adekanle DA, Adeyemi AS, Olowookere SA, Akinleye CA (2015) Health workers' knowledge on future vascular disease risk in women with preeclampsia in South Western Nigeria. BMC Res Notes 8: 576-581.

32. Bigdeli M, Zafar S, Assad H, Ghaffar A (2013) Health system barriers to access and use of magnesium sulfate for women with severe preeclampsia and eclampsia in Pakistan: Evidence for policy and practice. Plos One 8(3): e59158.

33. Osungbade KO, Ige OK (2011) Public health perspectives of preeclampsia in developing countries: implication for health system strengthening. J Pregnancy, p. 481095.

34. Danmusa S, Coeytaux F, Potts J, Wells E (2016) Scale-up of magnesium sulfate for treatment of preeclampsia and eclampsia in Nigeria. Int J of Gynecol Obstet 134(3): 233-236.

\section{Your next submission with Juniper Publishers will reach you the below assets}

- Quality Editorial service

- Swift Peer Review

- Reprints availability

- E-prints Service

- Manuscript Podcast for convenient understanding

- Global attainment for your research

- Manuscript accessibility in different formats

( Pdf, E-pub, Full Tsext, Audio)

- Unceasing customer service

Track the below URL for one-step submission

https://juniperpublishers.com/online-submission.php 